\title{
Zebrafish As a biomedical model for Stem Cells Research in Hearing impairment
}

\author{
Salma Hafeez
}

Student, Department of Biology, Virtual University of Pakistan, Lahore.

\begin{abstract}
Zebrafish is an excellent model for observing human genetic disorders. Hearing impairment is the most common genetic disorder including syndromic \& non-syndromic hearing loss. Stem cells therapies are considered a new hope in case of hearing impairment. Stem cells are the master cells of the human body and having the capability to differentiate into any other form of cells more than 200 types of cells (regeneration). This review article describes zebrafish as a biomedical model for stem cell research in hearing impairment, which revolutionized the biomedical arena to compete for the challenges.
\end{abstract}

Keywords: Biomedical model, hearing impairment, regeneration, stem cells, zebrafish.

\section{Introduction}

Zebrafish (Danio rerio) is a small fish with big data belongs to family Cyprinidae. Zebrafish is an excellent model organism for the study and observation of human genetic diseases. The unique feature of zebrafish such as large fertility rates, transparency \& optic clearance makes it remarkable biomedical model in stem cell research for genetic studies. Also, $70 \%$ of genome similarity of zebrafish with human make it a significant model for scientific research [1]. Hearing impairment is the most common genetic disorder caused by external \& inner ear anomalies [2]. There is large no of genes which are involved in hereditary sensorineural hearing loss and the cellular signalling mechanism of the development of the ears [3]. Stem cell therapy considered a new hope in the restoring hearing balance \& regenerative stem cells therapy of cell associated with the auditory function will make it possible to cure the hearing impairment [4].

\section{Wnt \& FGF pathway \& its Role in the neuromast of zebrafish:}

The zebrafish lateral line is an excellent model of the sensory network made up of mechanosensory hair cells called neuromast. These mechanosensory hair cells are similar in function \& mechanism as the vertebrate hair cells of the inner ear. In this way, these are the excellent model system for observing the hair cells molecular mechanism related to hearing \& balance to understand their genetic control. The unique properties of these hair cells of zebrafish in the lateral line are their regenerative capability, which makes them an excellent model for scientific research. Thus the molecular signalling pathway of these hair cells regeneration has great biomedical importance. Wnt and FGF pathway are crucial signalling pathway that is found in various organs and are considered as an important regulator for the development of the auditory organs. Wnt \& FGF signalling pathway leads to promote cell proliferation during neuromast development. The FGF pathway via FGF3, FGF10 promote cell proliferation of hair cell in the zebrafish \& Wnt inhibit these pathways via FGF1 during the developing \& regeneration of the neuromast. The Wnt \& FGF pathway control the cell proliferation, to provide strong evidence to manipulate these crucial pathways in the vertebrate inner ear to promote hair cells regeneration. The FGF signalling pathway has a crucial role in the development of the inner ear. Both Wnt \& FGF pathways are closely interacted to stimulate the cell proliferation during early neuromast development in the zebrafish( Fig 1) \& regenerate the cell proliferation in case of damage in the neuromast of zebrafish [5]. The zebrafish lateral line neuromast shows the specific inhibition of MYC as well as FGF signalling pathways for hair cells proliferation 
\& regeneration [6].

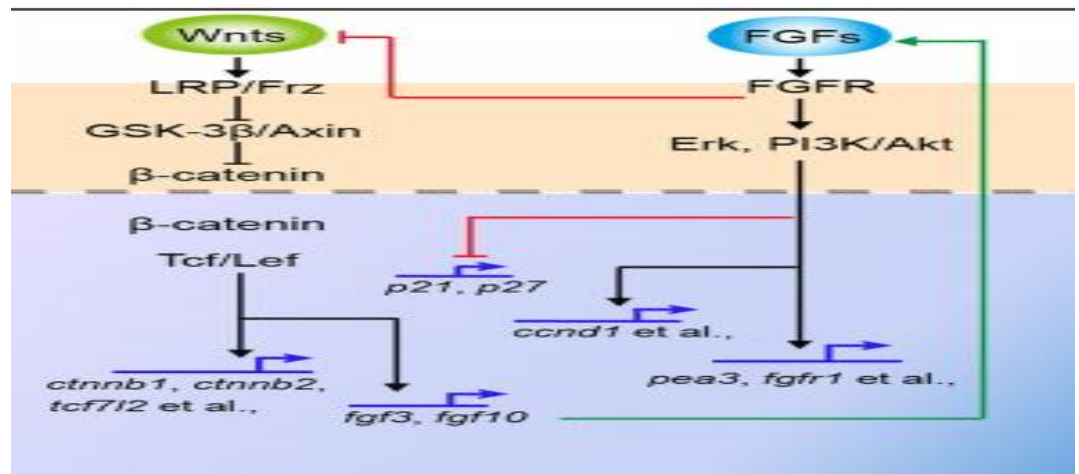

Figure 1 Wnt \& FGF signalling pathway [5].

\section{Connexin 26 mutation \& hearing loss in transgenic zebrafish:}

The mutation in the (GJB2) Gap Junction Beta 2 gene that encoded human connexin 26 (CX26) protein and (GJB6) Gap Junction Beta 6 gene encoded the connexin 30 (CX30) protein plays a crucial role in the nonsyndromic hearing loss. The connexin 26 and CX30 has an important role in the potassium circulation in the cochlea to maintain normal auditory physiology \& function, as connexin 26 and connexin 30 are found abundant in the cochlear supporting cells both in human \& mice model [7]. The zebrafish is an excellent biomedical model for research on the inner ear of vertebrates \& hearing impairment. As the genome of zebrafish is highly orthologous to the human genome to provide a better platform for vertebral development \& pathogenic visualization and manipulation due to similarity with the human inner ear, as there are two sensory epithelia in the otic vesicle in the zebrafish i-e anterior utricular macula \& posterior saccular macula to perform auditory \& vestibular function.CX26 \& CX30 mutations in zebrafish as well as in human give a similar expression pattern in the inner ear. The authors analyzed the orthologous mutation of CX26 in the zebrafish otic vesicles with Arg2 protein as it acts as a promoter for genetic expression of otic vesicles of zebrafish to investigate the CX26 mutation $\&$ its effects on mutated CX30 in the otic vesicles in the inner ear to find out its behavior \& function. The variant of zebrafish shows the alignment of the amino acid sequence of human CX26 \& mutated CX30 in zebrafish indicating homologous one (Fig 2). The mutation of CX30 shows structural alteration in the inner ear. In the transgenic zebrafish, the mutation of CX30 is caused by decreased mechanosensory perception \& instability in swimming. The CX26 \& CX30 are homologous protein in term of subcellular location that affects the function of inner ear and development of inner ear by structural changes of the otolith. The mutation in CX26 \& CX30 in transgenic zebrafish shows cellular anomalies that changed the anatomy of the inner ear [8].

\section{The regeneration of hair cells in the zebrafish:}

The genetics of zebrafish is helpful to study regeneration to find out genes involved in healing processes that lack in mammals. This large -scale genetic screen of neuromast development in zebrafish provides an essential platform for hair cells regeneration as well as in tissue regeneration. The authors analyzed the genetic screen involving 254 stable genetic mutations on hair cells regeneration. As a result, seven genes i-e hspd1, hspe1, hspa13, rnpc3, gem5, hspal $3 \&$ mgat 5 are identified that are considered essential for hair cells regeneration. These seven regeneration genes are categorized in three functional groups: 1) heat shock protein (hspd1,hspel,hspa13), 2) RNA splicing factor (rnpc3,gem5,hspal3), and 3) glycosylation enzyme (mgat5). These three functional group consists of one enhancer \& six inhibitors of regeneration(Fig 3). The regenerative mechanism of theses 7 genes in the zebrafish 
provides essential guidance for development $\&$ design of regenerative medicine for restoring injured $\&$ damage tissue in human [9]. The neuromast of the zebrafish lateral line can regenerate mechanosensory hair cells after severe injury and its epithelium serves as a network for intracellular communication for repair \& regeneration of hair cells gives a new direction in the therapies of hearing impairment [10]. The gene SOX2 and SOX 3 has a crucial role in the formation of neural \& sensory progenitors in the inner ear of mammals. The zebrafish as a model animal shows the SOX2 gene is needed for sensory development \& SOX3 is required for neurogenesis [11]. The damage in the sensory hair cell leads to deafness \& inner ear anomalies. In contrast to mammalian ear, zebrafish lateral line hair cells tend to proliferate to regenerate them by supporting cells. The scRNA-seq analysis determined the FGF \& Notch signalling by inhibiting the proliferation of supporting cells in the lateral line of zebrafish for the regeneration of mechanosensory hair cells [12]. The Schwann cells in the neuromast of the zebrafish have the potential to regenerate \& differentiate progenitor for hair cells by ErbB signalling [13].

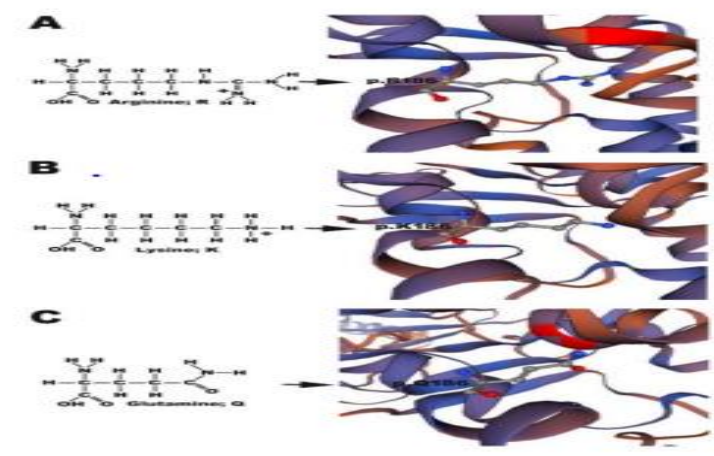

Figure 2 Structural simulation of CX30 proteins [8].



Figure 3 Regeneration expression in the neuromast of zebrafish [9]

\section{micro-RNA 183:}

miRNAs are the small non-coding RNAs comprised of 20-22 nucleotides that are functional in RNA silencing \& regulation of gene expression for development \& differentiation in various organs [14]. Also, miRNA-183 cluster has a specific role in the development $\&$ function of sensory organs especially inner ear [15]. The miRNA-183 family clusters are expressed in the inner ear sensory cells in the zebrafish [16]. The miRNA-183 considered an essential therapeutic approach for hearing impairment. In the zebrafish, miRNA-183 identified a significant role in hair cell development (ectopic hair cell growth) as well as in hair cells regeneration. The regulatory role of miRNA-183 in the zebrafish induced hair cells degeneration under stressful condition may use in the mammalian 
inner ear. It regulates p53 gene that regulates cells apoptosis, in this way miRNA-183 cluster plays an essential role in the stimulation of hair cells regeneration by regulating signal molecules that are involved in transdifferentiation of hair cells after ototoxic damage \& helpful to develop a potential drug target for hearing impairment [17].

\section{Stem cells research in the hearing impairment:}

The stem cells therapies are considered a new hope in hearing impairments. Stems cells are the master cells of the body that can differentiate into more than 200 types of cells. The regenerative ability of stem cell gives direction to differentiate them in mechanosensory hair cells \& nerves cells for the therapeutic approach of hearing impairment [18]. miRNA plays a crucial role in the development of hair cells \& cochlea. It also participates in the proliferation of stem cells in the regeneration of hair cells of the inner ear to restore hearing loss [19]. Also, stem cells homing factor is an essential mechanism to utilize the mesenchymal stem cells for transplantation of cochlear tissue in the inner ear for recovery of hearing loss [20].

Table 1. Genes \& its attributes associated with stem cells research in hearing impairment in a model organism (Zebrafish)

\begin{tabular}{|c|c|c|c|c|}
\hline S.No & Genes & $\begin{array}{l}\text { Expression of genes in the } \\
\text { model organism (Zebrafish) }\end{array}$ & $\begin{array}{c}\text { Functions of genes in the model } \\
\text { organism (Zebrafish) }\end{array}$ & References \\
\hline 1 & FGFR1 & \multirow[t]{3}{*}{ FGF signalling pathway } & \multirow{3}{*}{$\begin{array}{l}\text { Regulator for the development of auditory } \\
\text { organs, the proliferation of hair cells as } \\
\text { well as the development of inner ear }\end{array}$} & \multirow{5}{*}{ [5] } \\
\hline 2 & FGFR3 & & & \\
\hline 3 & FGFR10 & & & \\
\hline 4 & TCF & Wnt signalling pathway & $\begin{array}{l}\text { Hair cells proliferation and regeneration } \\
\text { of neuromast. }\end{array}$ & \\
\hline 5 & GJB2 & Connexin26 (CX26) & \multirow{2}{*}{$\begin{array}{l}\text { It maintains normal function \& } \\
\text { development of the inner ear. }\end{array}$} & \\
\hline 6 & GJB6 & Connexin30 (CX30) & & {$[7-8]$} \\
\hline 7 & HSPE1 & \multirow[t]{2}{*}{ Heat shock proteins } & \multirow{7}{*}{$\begin{array}{l}\text { Essential for hair cells regeneration, } \\
\text { neuromast development \& regeneration. }\end{array}$} & \multirow{7}{*}{ [9] } \\
\hline 8 & HSPD1 & & & \\
\hline 9 & HSPA13 & $\begin{array}{l}\text { Heat shock protein, RNA } \\
\text { splicing factor }\end{array}$ & & \\
\hline 10 & RNPC3 & \multirow[t]{2}{*}{ RNA splicing factors } & & \\
\hline 11 & GEM5 & & & \\
\hline 12 & MGAT5 & Glycosylation enzyme & & \\
\hline 13 & SMN1 & $\begin{array}{l}\text { SMN ( survival of motor } \\
\text { neuron) protein }\end{array}$ & & \\
\hline
\end{tabular}




\begin{tabular}{|l|l|l|l|c|}
\hline 14 & SOX2 & Transcription factor & $\begin{array}{l}\text { Hair cell proliferation, neurogenesis, neural } \\
\text { \& sensory progenitors in the inner ear. }\end{array}$ & {$[11]$} \\
\hline 15 & SOX3 & $\begin{array}{l}\text { DNA-binding transcription } \\
\text { factor }\end{array}$ & $\begin{array}{l}\text { Hair cell proliferation, neurogenesis, } \\
\text { development of neural \& sensory } \\
\text { progenitors in the inner ear }\end{array}$ \\
\hline 16 & P53 & Tumor protein TP53 & $\begin{array}{l}\text { cells apoptosis, stimulation of hair cells } \\
\text { regeneration }\end{array}$ & {$[17]$} \\
\hline
\end{tabular}

\section{Future perspective:}

The zebrafish is a suitable biomedical model for the genetic study of hearing impairment. The FGF \& Wnt interactive pathway contribute to cells proliferation for regenerative purpose in the neuromast of zebrafish. The transparent visualization \& manipulation makes zebrafish an excellent model for monitoring the genetic screening \& technique of CRISPR-Cas9 in stem cells research of genome editing in hearing impairment. It is an outstanding biomedical model for stem cells research for hearing loss to overcome the challenges.

\section{Conclusion:}

It is concluded that zebrafish is the best biomedical model for stem cells research due to its transparent visualization of genetic screening. The mechanosensory hair cells in the neuromast of zebrafish $\&$ its regenerative capabilities make it best model animal for inner ear therapy. But still, there are gaps to reach the therapeutic goal of hearing impairment. The mechanism of the signalling pathway of gap junctions, FGF, SHP-2, SIX1 and SALL1 proteins are still questionable in the model organism to overcome the congenital hearing loss in human.

\section{Acknowledgement}

Foremost, all praise to Almighty Allah for blessing me with strength and enabling me to complete this work.

\section{References}

1. Tavares B, Lopes SS. The importance of Zebrafish in biomedical research. Acta medica portuguesa. 2013 Oct $31 ; 26(5): 583-92$.

2. Del Castillo FJ, Del Castillo I. DFNB1 non-syndromic hearing impairment: Diversity of mutations and associated phenotypes. Frontiers in molecular neuroscience. 2017 Dec 22; 10:428.

3. Bademci G, Cengiz FB, Foster Ii J, Duman D, Sennaroglu L, Diaz-Horta O, Atik TA, Kirazli TA, Olgun L, Alper HÜ, Menendez I. Variations in multiple syndromic deafness genes mimic non-syndromic hearing loss. Scientific reports. 2016 Aug 26; 6(1):1-7.

4. Kamiya K. Inner ear cell therapy targeting hereditary deafness by activation of stem cell homing factors. Frontiers in Pharmacology. 2015 Jan 27;6:2

5. Tang D, He Y, Li W, Li H. Wnt/ $\beta$-catenin interacts with the FGF pathway to promote proliferation and regenerative cell proliferation in the zebrafish lateral line neuromast. Experimental \& molecular medicine. 2019 May 23; 51(5):1-6. 
6. Lee SG, Huang M, Obholzer ND, Sun S, Li W, Petrillo M, Dai P, Zhou Y, Cotanche DA, Megason SG, Li H. Myc and Fgf are required for zebrafish neuromast hair cell regeneration. PLoS One. 2016 Jun 28; 11(6):e0157768.

7. Johnson SL, Ceriani F, Houston O, Polishchuk R, Polishchuk E, Crispino G, Zorzi V, Mammano F, Marcotti W. Connexin-mediated signaling in nonsensory cells is crucial for the development of sensory inner hair cells in the mouse cochlea. Journal of Neuroscience. 2017 Jan 11; 37(2):258-68.

8. Su HA, Lai TW, Li SY, Su TR, Yang JJ, Su CC. The Functional Role of CONNEXIN 26 Mutation in Nonsyndromic Hearing Loss, Demonstrated by Zebrafish Connexin 30.3 Homologue Model. Cells. 2020 May; 9(5):1291.

9. Pei W, Xu L, Huang SC, Pettie K, Idol J, Rissone A, Jimenez E, Sinclair JW, Slevin C, Varshney GK, Jones M. Guided genetic screen to identify genes essential in the regeneration of hair cells and other tissues. NPJ Regenerative medicine. 2018 Jun 4; 3(1):1-1.

10. Pinto-Teixeira F, Viader-Llargués O, Torres-Mejía E, Turan M, González-Gualda E, Pola-Morell L, López-Schier H. Inexhaustible hair-cell regeneration in young and aged zebrafish. Biology open. 2015 Jul 15; 4(7):903-9.

11. Gou Y, Vemaraju S, Sweet EM, Kwon HJ, Riley BB. Sox2 and Sox3 play unique roles in development of hair cells and neurons in the zebrafish inner ear. Developmental biology. 2018 Mar 1; 435(1):73-83.

12. Lush ME, Diaz DC, Koenecke N, Baek S, Boldt H, St Peter MK, Gaitan-Escudero T, Romero-Carvajal A, Busch-Nentwich EM, Perera AG, Hall KE. ScRNA-Seq reveals distinct stem cell populations that drive hair cell regeneration after loss of Fgf and Notch signaling. Elife. 2019 Jan 25; 8:e44431.

13. Sánchez M, Ceci ML, Gutiérrez D, Anguita-Salinas C, Allende ML. Mechanosensory organ regeneration in zebrafish depends on a population of multipotent progenitor cells kept latent by Schwann cells. BMC biology. 2016 Dec 1; 14(1):27.

14. Chang Woo Kim, Ji Hyuk Han, Ling Wu, and Jae Young Choi. MicroRNA -183 is essential for hair cell regeneration after neomycin injury in zebrafish. Yonsei Medical Journal 2018 Jan; 59(1): pp.141-147

15. Geng R, Furness DN, Muraleedharan CK, Zhang J, Dabdoub A, Lin V, Xu S. The microRNA183/96/182 cluster is essential for stereociliary bundle formation and function of cochlear sensory hair cells. Scientific reports. 2018 Dec 21; 8(1):1-3.

16. Fogerty J, Stepanyan R, Cianciolo LT, Tooke BP, Perkins BD. Genomic non-redundancy of the mir183/96/182 cluster and its requirement for hair cell maintenance. Scientific reports. 2019 Jul 16; 9(1):1 - 
5.

17. Chang Woo Kim, Ji Hyuk Han, Ling Wu, and Jae Young Choi MicroRNA -183 is essential for hair cell regeneration after neomycin injury in zebrafish. Yonsei Medical Journal 2018 Jan; 59(1): pp.141-147

18. Zhengqing $\mathrm{Hu}$, and Mats Ulfendahl. "The potential of stem cells for the restoration of auditory function in humans Regenerative. Medicine 2013 May; 8(3): pp.309-318

19. Wu X, Zou S, Wu F, He Z, Kong W. Role of microRNA in inner ear stem cells and related research progress. American Journal of Stem Cells. 2020; 9(2):16.

20. Kamiya K. Inner ear cell therapy targeting hereditary deafness by activation of stem cell homing factors. Frontiers in Pharmacology. 2015 Jan 27;6:2 